\title{
Mechanisms that Regulate Recovery of Consciousness in Patients in Vegetative State/Unresponsive Wakefulness Syndrome: A New Model
}

\section{Giuliano Dolce*}

RAN - Research on Advanced Neuro-rehabilitation, S. Anna Institute, Crotone, Italy

\section{Description}

In recent years the neurosciences have made a marked contribution to enriching the understanding of mechanisms that regulate brain functions. Nevertheless, the treatment of severe disorders of consciousness that characterize Vegetative State/Unresponsive Wakefulness Syndrome (VS/UWS) [1] has continued to take an essentially empirical line that fails to take into consideration progress in neuro-physiopathology. To enable the recovery of conscious activity that has been reduced to a minimum by severe acquired brain disease, first of all it is necessary to define, from a neurological point of view, the mechanisms that regulate it in order to plan a scientifically-based treatment approach. For over 50 years neurophysiology has described the important separate brain structures involved in the functions of consciousness. For example the role of nonspecific activating afferents composed of the reticular formation maintaining wakefulness was described by Moruzzi and Magoun 1949 [2].

In 1965 the German neurologist Richard Jung put forward the basis of a theory which might be defined as the theory of coherence [3]. Jung defined consciousness, strictly from a neurological point of view, as a basal functional state of the brain without which individual neurological functions are not possible. This particular state manifests in wakefulness only when certain major systems and not simple anatomo-functional structures activate simultaneously and mutually in a certain determined degree of activation. Jung proposed three major systems: 1) the specific afferent system, which allows the brain to receive all the sensorial information that comes from the world outside; 2) the nonspecific ascending reticular system, which regulates not only the excitability of the cortical neurons facilitating or inhibiting by occlusion mechanisms and the passage of information from the specific sensorial system, but also the excitability of all the peripheral receptors [4]; and 3 ) the medium frequency of cortical neuron discharge: when this is very high, a state of seizure state occurs, whereas when it is too low a state of coma occurs; both of these conditions are incompatible with wakefulness. In 2002, based on research by Hassler [5] fourth system was added to the other three: ipsilateral and contralateral primary motor systems [6].

Hassler clearly describes two primary motor systems: the vestibularspinalsystem for ipsilateral movements and the more complex pallidalthalamic-cortical-pallidal system for contralateral movements. These subcortical primary motor systems are joined by the cortical systems; first of all Brodmann prefrontal area 8.

The importance of spontaneous movement as an integral and inescapable part of the mechanisms that regulate conscious activity is highlighted by several observations in clinical neurology. For example, bilateral coagulation of the pallidal system performed during stereotactic surgery to treat Parkinson's disease produced an apallic syndrome in the patient, which is the same as what is nowadays called UWS/VS. Moreover even at the end of the 1960' bilateral stimulation of the pallydal system in three patients in posttraumatic VS/UWS for six months had produced a behavioral awakening and an evident arousal in EEG [7]. Congenital bilateral aplasia of Brodmann area 8 (prefrontal area which induces contraversive movements)causes pseudo-Bálint's syndrome, a striking clinical example: if the body cannot move and lateral eye movements are blocked, even if there is no damage to the visual system, perception is not possible and the objects placed in front of the retina are not seen. Besides the cortical areas, which are well known, the subcortical mechanisms for sideways movement also play an important role in processes of apperception. Kleist [8] had already spoken of an "optomotorisches system" and also described auditory motor, olfactory and gustative motor systems. Undoubtedly there are motor systems proximal to the primary sensory areas, which, together with the subcortical areas that form the pallido-thalamo-corticopallidal loop, have the task of turning the subject towards the source of sensory input. Each sensory system has its own regulatory motor apparatus. Apperception is a complex cortical function that occurs outside the specific sensory areas thus enabling the peculiar features of the object being observed to be recognized.

Finally, in a study on the clinical evolution of over 1000 patients in VS/UWS, Dolce and co-workers observed the most severe neurological sign that characterizes the syndrome was the absence of movement. It was possible, after only 50 days from the event, to forecast the outcome with a high level of reliability in the absence of movement. Nine months after the event half of the patients remained in Glasgow Outcome Scale (GOS). class 2 and the other half in class 1 (death). [9,10]. These are the reasons that prompted us into thinking that spontaneous motility is the fourth major system that regulates that particular functional state of the brain that enables wakefulness. More recently, over the last 10 years in the RAN (Research in Advanced Neurorehabilitation) laboratory we found that it was possible to get some response.

During sensory stimulation in patients in VS/UWS we have observed that responses can be obtained only when the patient is relaxed, but even these results are not constant or repeatable. Fluctuations in the state of wakefulness were frequent throughout the course of the day [11]. Polygraph recording of various parameters throughout the experimental study to obtain the "mom effect" [12] showed that it is possible to record the physical correlates of emotions by observing modifications in the psychogalvanic reflex, and more importantly, modifications of the Heart Rate Variability (HRV). An articulated sequence of algorithms has enabled a pinpointing of the exact moment when a determined balance between the vagal vegetative and the sympathetic system occurs, a moment when there is a greater

*Corresponding author: Giuliano Dolce, RAN - Research on Advanced Neuro-rehabilitation, S. Anna Institute, Via Siris - IT-88900 Crotone, Italy, Tel: 00393471129531; E-mail: giulianodolce@libero.it

Received May 23, 2015; Accepted August 06, 2015; Published August 14, 2015

Citation: Dolce G (2015) Mechanisms that Regulate Recovery of Consciousness in Patients in Vegetative State/Unresponsive Wakefulness Syndrome: A New Model. Brain Disord Ther 4:178. doi:10.4172/2168-975X.1000178

Copyright: (c) 2015 Dolce G. This is an open-access article distributed under the terms of the Creative Commons Attribution License, which permits unrestricted use, distribution, and reproduction in any medium, provided the original author and source are credited. 
Citation: Dolce G (2015) Mechanisms that Regulate Recovery of Consciousness in Patients in Vegetative State/Unresponsive Wakefulness Syndrome: A New Model. Brain Disord Ther 4:178. doi:10.4172/2168-975X.1000178

likelihood of obtaining behavioral responses, which is an indication of a possible evolution towards a minimal state of wakefulness [13]. This suggests that besides the four major systems a fifth system should also be considered: the Central Autonomic Network (CAN) which comprises several structures: the limbic gyrus, insula, prefrontal and parietal cortex $[14,15]$. Although the degree of activation of the first four major systems is hard to assess with objective measures, the functional state of the CAN, can be assessed by modifications of the HRV. Thus, the mode of multisensory stimulation guided by the patient in VS/UWS is indicated only when the CAN is in a particular set-up, which is indicated by HRV detection. In a pilot study a group of six patients were stimulated by this method for 40 minutes a day, for two months with a frequency of five times a week following a specific protocol [16] and the results were compared with those of a control group of six patients treated by the same method but without being monitored by HRV analysis. Five of the six patients treated by the guided sensory regulation method had come out of the VS/UWS within six weeks, whereas in only one patient of the control group were there signs of modification in the activity of wakefulness [11,13,17-19].

In conclusion, it can be said that the coherence theory on neurological mechanisms that regulate wakefulness has shown to be acceptable because it enables a therapeutic approach to be elaborated on a scientific and not only on an empirical basis. The vegetative nervous system plays an important role in realizing that particular functional state of the brain, called wakefulness, that enables all other functions to be carried out, especially those that put it in touch with the outside world. From a speculative point of view, the C.A.N. might be considered not simply as a major system like the other four so far identified, but as playing the part of pace-maker for all the other systems that have to be involved [20].

\section{Acknowledgements}

I would like to thank Dr. Lucia Lucca and Dr. Francesco Riganello, who in the last 10 years have cooperated with skill and enthusiasm in the RAN (Research in Advanced Neurorehabilitation) labs of the St Anna Institute of Crotone.

\section{References}

1. Laureys S, Celesia G, Cohadon F, Lavrijsen J, Leon-Carrion J, et al. (2010) The European Task Force on Disorders of Consciousness: Unresponsive wakefulness Syndrome: a new name for the vegetative state or apallic syndrome. BMC Medicine 8: 68

2. Moruzzi G, Magoun HW (1949) Brain stem reticular formation and activation of the EEG. ElectroencephalogrClinNeurophysiol 1: 455-473.

3. Jung R (1965) AufmerksamkeitunfBewustseinmitihtemphysiologischenBedingungen in Psychiatrie der Gegenwart. Springer 612-646.

4. DolceG,FrommH(1972)Beeinflussung desvisuellevoziertenReaktionspotentials (VRP) durchVeranderung der spezifischen und unspezifischenAfferenzen der Area striata. Z EEG-EMG. 1: 100-108.
5. Hassler R, Rolle Y, Streicher H (1972) Pathophisiologie der Bewustseintatigkeit Thieme Medical Publishers, Stuttgart, Germany.

6. Dolce G, Sazbon L (2002) The post-traumatic vegetative state. Thieme Medical Publishers, Stuttgart, Germany.

7. Hassler R, Dalle Ore G, Dieckmann G, Bricolo A, Dolce G (1969) Behavioural and EEG arousal induced by stimulation of unspecific projection systems in a patient with post-traumatic apallic syndrome. ElectroencephalogrClinNeurophysiol 27 306-310.

8. KleistK (1937) Berichtüber die Gehirnpathologie in ihrerBedeutungfürNeurologie und Psychiatrie. Z FürGesamteNeurolPsychiatr 158: 159-193.

9. Dolce G, Quintieri M, Serra S, Lagani V, Pignolo L (2008) Clinical signs and early prognosis in vegetative state: a decisional tree, data-mining study. Brain Inj 22: 617-623.

10. Dolce G, Arcuri F, Carozzo S, Cortese MD, Greco P, et al. (2015) Care and Neurorehabiliton in the disorder of counsciouness:a model in progress The Scientific World Journal.

11. Cortese MD, Riganello F, Arcuri F, Pugliese ME, Lucca LF, et al. (2015) Coma Recovery scale $-\mathrm{R}$. Variability in thedisorder of counsciousness. BMC Neurol in press.

12. Dolce G, Riganello F, Quintieri M, Candeleri A, Conforti D (2008) Personal interaction in the vegetative state: A data-mining study. JPsychophysiol 22: 150-156.

13. Riganello F, Giuliano D, Garbarino S, Sannita WG (2014) Heart rate variability and the two -way interaction between CNS and the centra autonomic network. ExpcliCardiol 20: 5584-5595.

14. Riganello F, Cortese MD, Dolce G, Sannita WG (2013) Visual pursuit response in the severe disorder of counscious: modulation by the central autonomic system and a predictive model. BMC Neurol 13: 164

15. Riganello F, Garbarino S, Sannita WG (2012) Heart rate variability Homeostasis and Brain function. A tutorial and review of application. JPsychophysiol 26: 178-203.

16. Riganello F, Cortese MD, Arcuri F, Dolce G, Lucca MF, et al. (2015) Measuring the autonomic nervous systam functional state improves neurorhabilitationaoutcome in doc. Jneurotrauma in press.

17. Cortese MD, Riganello F, Arcuri F, Pugliese ME, Lucca LF, et al. (2015) Coma Recovery Scale-R: Variability In The Disorder Of Consciousness. BMC Neuro in press.

18. Candelieri A, Cortese MD, Dolce G, Riganello F, Sannita WG (2011) Visua Pursuit: Within-Day Variability in the Severe Disorder of Consciousness. J Neurotrauma 28: 2013-2017.

19. Riganello F, Dolce G, Garbarino S, Sannita WG (2014) Heart rate variability and the two-way interaction between CNS and the central autonomic network. ExpClinCardiol 20: 5584-5595

20. Riganello F, Garbarino S, Sannita WG (2012) Heart Rate Variability Homeostasis, and Brain Function: A Tutorial and Review of Application. J Psychophysiol 26: 178-203.

21. Riganello F, Cortese MD, Arcuri F, Dolce G, Lucca MF, et al. (2015) Measuring the autonomic nervous system functional state improves neurorehabiliation outcome in doc. $\mathrm{J}$ Neurotrauma in press. 